Historia y comunicación social

ISSN-e 1988-3056

https://dx.doi.org/10.5209/hics.66309

\title{
Perversas, seductoras y villanas: La construcción de la mujer fatal en la telenovela latinoamericana
}

\author{
Tatiana Hidalgo-Marí1
}

Recibido: 26 de julio de 2017. / Aceptado: 15 de julio de 2018.

Resumen. Desde la consolidación de las telenovelas, el estereotipo de la mujer fatal, concebido como mujer seductora y persuasiva, causante de los males del mundo, se ha configurado en ellas como la villana antagonista por excelencia, influyendo directamente en la construcción social de la mujer. Este trabajo, mediante una metodología cualitativa basada en un análisis documental de enfoque semiótico, analiza cómo la telenovela se apropia del estereotipo de la mujer fatal, lo estandariza y lo configura de forma personalizada en sus discursos narrativos.

Palabras clave: discurso; estandarización; estereotipo; mujer fatal; televisión; telenovela.

\section{[en] Perverses, seductive and villainous: The construction of the femme fatale in the Latin American TV soaps}

\begin{abstract}
From the consolidation of soap operas, the stereotype of the femme fatale, conceived as a seductive and persuasive woman and the causer of the evils of the world, is configured as the antagonistic villain by excellence, directly influencing the social construction of women

This work, using a qualitative methodology based on a documentary analysis with a semiotic approach, analyzes how the telenovela has appropriated the stereotype of the femme fatale, standardizes it and configures it in a personalized way in its narrative discourses.

Keywords: speech; standardization; stereotype; femme fatale; TV; soap opera.

Sumario: 1. Introducción. 2. La mujer fatal en clave sociocultural. 3. Metodología. 4. Resultados. 4.1. De la construcción física de la mujer fatal. 4.2. Sobre el perfil psicológico de la mujer fatal. 4.3. De su relación con el resto de personajes. 4.4. De su protagonismo en la narración. 5. Conclusiones. 6. Referencias bibliográficas.
\end{abstract}

Cómo citar: Hidalgo-Marí, T. (2019). Perversas, seductoras y villanas: La construcción de la mujer fatal en la telenovela latinoamericana, en Historia y comunicación social 24 (2), 699-712.

\footnotetext{
$1 \quad$ Universidad de Alicante. tatiana.hidalgo@ua.es
} 


\section{Introducción}

Hablar de telenovela es hacer referencia a un producto de consumo, un género de entretenimiento audiovisual, "un vehículo de creación destinada al entretenimiento colectivo" (Cueva, 1998, p.7). A través de la circulación de este producto cultural, se construye una de las modalidades del imaginario latinoamericano, un espacio en el que se eliminan las fronteras y surge un discurso homogéneo, basado en una imagen unificada de lo popular (Martín-Barbero, 1992, p.25).

La telenovela, entendida como un género televisivo, forma parte de la dinámica cultural de una sociedad y tiene una finalidad mediática porque funciona dentro de un sistema productivo concreto, atiende a las lógicas del consumo y reproduce al mismo tiempo esquemas culturales (Carvajal \& Molina y 1999).

Teniendo en cuenta que la telenovela es el producto televisivo más constante y reconocido de Latinoamérica (Mazziotti, 1996, p.17), debemos entender que todo su discurso cultural afectara directamente a la construcción social que la sustenta. En ese sentido, la construcción de una imagen femenina dentro de las telenovelas se convierte en un discurso social necesario de estudiar, puesto que es capaz de afectar a la construcción social de la mujer y de la propia sociedad. Como han defendido algunos autores, esta influencia en el constructo social es el motivo por el que las mediaciones de la telenovela se producen en esferas productoras de significados, como pueden ser instituciones, escuelas, barrios o familias, todas ellas, escenarios cotidianos (Carvajal \& Molina, 1999).

La telenovela permite al espectador organizar la experiencia vivida, y mantener la ilusión en la superación y la resolución de problemas (González Rubín, 2007). Todo problema tendrá una solución, aportando así una implicación socioeducativa que reflejará las posibilidades ante las desgracias, como si de una lección moral se tratara. La telenovela, pues, también busca educar la conducta básica diaria del espectador y alegar la esperanza y la constancia como herramienta de resolución de los problemas (Roura, 1993, p.45).

El estudio de la representación femenina dentro de la telenovela adquiere mayor importancia si tenemos en cuenta que el género de la telenovela actúa como matriz de cultura popular y tradicional que se perpetúa como parte integrante de la cultura de masas. Es el género popular, lo que refleja una serie de realidades patentes (muchas veces llevadas al extremo) que generan en el espectador-consumidor una sensación de sosiego en el momento que percibe las penurias ajenas y olvida, o menos, sus propios problemas (Morin, 1966). Además, centrándonos en un estereotipo femenino, debemos profundizar en la construcción social de la mujer y en cómo los propios productos televisivos influyen en la configuración del discurso cultural.

Los personajes estereotípicos sobre los que se conjugan los discursos culturales y sociales en las telenovelas son, fundamentalmente: la víctima, el traidor, el justiciero y el bobo (Lataban, 1995, p.54). En este sentido, el estudio de una representación femenina que tradicionalmente ha sido perpetuada como la traidora, villana y antagonista, resulta muy relevante como aspecto sociocultural dentro de la configuración del discurso narrativo de las telenovelas y su contribución al discurso social alrededor de la mujer.

Partiendo de la premisa de que el estereotipo supone una herramienta infalible en la construcción de la realidad televisiva, ya que permite una rápida y eficaz comprensión del planteamiento de la ficción, sustentando modelos de repetición fácil- 
mente identificables (Lippmann, 1922; Wolf, 1987; Miller, 1999), resulta pertinente analizar en profundidad la representación del estereotipo femenino en cuestión para poder valorar la estandarización en clave postindustrial que se hace del mismo en la pequeña pantalla.

Además, no podemos obviar que los productos culturales en general, y de las narrativas televisivas en particular, tienen la capacidad de reestructurar los contenidos estereotípicos clásicos para generar nuevos patrones, nuevas tendencias y/o personajes que permiten reinventar los contenidos tradicionales (Autor, 2015, p.4). Este proceso de reinvención responde a las lógicas de la estandarización y de la intercambiabilidad de las partes, procesos que han sido muy estudiados en el seno de la producción de las industrias culturales. (Adorno \& Horkheimer,1998; Rodríguez-Ferrándiz, 2008). Las telenovelas, entendidas como un género televisivo y, por ende, un producto cultural, asumieron fielmente desde sus orígenes la representación más pura de la imagen de la mujer fatal y dieron lugar a la consagración del mito en la ficción televisiva. A través de la representación de mujeres con una sexualidad sobrevenida y con gran poder de actuación sobre una ficticia simplicidad masculina, continuaron con la expansión del mito a través de las pantallas televisivas (Autor, 2013, p.198). No obstante, entre sus personajes, la mujer fatal adquiere una nueva dimensión, una personalidad propia y se nutre de nuevas caracterizaciones, nunca antes atribuidas a la mujer fatal a lo largo de la tradición cultural. Por este motivo, el estudio de la construcción de la mujer fatal en el discurso de las telenovelas adquiere importancia, si tenemos en cuenta que esa configuración arroja nuevos significados al imaginario de la mujer fatal en la cultura contemporánea.

El objetivo del presente trabajo es aportar una radiografía sobre la construcción del estereotipo de la mujer fatal en la telenovela latinoamericana para poder establecer los aspectos innovadores que este género televisivo ha aportado a la construcción sociocultural del estereotipo de la mujer fatal, que aspectos han innovado y cómo han contribuido al desarrollo industrio-cultural del mismo. El estudio en profundidad de la mujer fatal permitirá constatar uno de los dos extremos opuestos de mujer que absorben las telenovelas: la mujer fatal, la villana por excelencia en contraposición a la buena mujer, la fiel y correcta, en un intento moralizador de dejar patente del triunfo del bien sobre el mal (Roura, 1993, p.45).

\section{La mujer fatal en clave sociocultural}

Hablar de la mujer fatal es hacer referencia directa a un personaje femenino cautivador, erótico y seductor, que utiliza su atractivo como herramienta de subsistencia y superación personal. Se ha definido como una mujer que: “(...) utiliza su atractivo como herramienta para embaucar a cualquier incauto que acabará convirtiéndose en un títere que manejará a su interés y que, irremediablemente, será conducido a un trágico final" (Bornay: 1990, p.49) o bien como: "mujer guapa que se aprovecha de los hombres con un móvil final, normalmente económico" (Bornay 1990, p.71).

Tradicionalmente, el imaginario de la cultura patriarcal ha representado la mujer encasillada en la dicotomía ángel/demonio. Existía una mujer sometida y abnegada al hombre, pasiva, de rasgos angelicales y otra caracterizada ser fuerte, activa y perjudicial para el hombre (Otto, 1970, p.131). Las primeras, las mujeres angelicales, son representadas como diosas relacionadas con el paraíso, encargadas de la 
fertilidad o las tierras; siempre son personajes divinizados, con rostros angelicales, pero sumisas a la figura creadora del hombre (Allen, 1983, p.26). Su presencia es poca y poco relevante. Cuando la mujer comienza a aparecer más profusamente en la mitología lo hace de manera perversa, portadora de los males y desgracias de la humanidad, como es el caso de Pandora o Eva.

Desde las primeras apariciones femeninas en la mitología, existe una dualidad que identifica a la mujer con el mal y la perversidad, mientras que el hombre es la representación del bien, del poder, ya la hora a la víctima de la fatalidad femenina: el género femenino, en los orígenes de la humanidad, no realiza ningún otro papel más allá de encarnar la fuerza del mal (González-Ovies, 1994, p.382). Se identifica a la mujer, pues, con la monstruosidad, con la astucia, la locura y la trampa. Se la representa capaz de llevar al hombre a la destrucción.

Aunque el arquetipo de la mujer fatal está presente en prácticamente todas las culturas, sus orígenes se remontan a la mitología más clásica. Esa mujer mortífera ha sido omnipresente en el folclore popular y el arte de la cultura occidental, aunque su resurgir florece en el arte de fines del siglo XIX y los inicios XX (Houvenaghel \& Monballieu 2008, p.854). Los pintores prerrafaelistas mostraron una especial fascinación por la mujer fatal, a la que representaban con una belleza turbia, perversa, sensual y orgánica, destructiva para el hombre: se trataba de mujeres activas, fuertes y sexualizadas, que surgían como respuesta a la amenaza del incipiente feminismo de la época. (Cruzado-Rodríguez, 2004, p.5). Los mitos principales que sientan las bases de la mujer fatal en la cultura occidental son el mito de Pandora (mitología) y el mito del pecado original de EVa (religión). En ambos casos, el mito primitivo de la perversidad femenina se ha convertido en la explicación ética de los males del mundo (Millet, 1991).

La mujer fatal ha sido reproducida y entendida como tema estético utilizado para contribuir a la historia de las imágenes de la feminidad y ha supuesto un engranaje importante en el contexto estético de cada momento (Hilmes, 1990; Canals, 2009). La mujer fatal se ha configurado como el modelo de mujer discordante, que no se somete a los cánones establecidos, que desafía las estructuras patriarcales y aprovecha sus grietas para obtener beneficio propio, material o simbólico (Gallego, 2013, p.218).

No obstante, en el estudio de la mujer fatal como imagen prototípica resurgida en la literatura y la pintura romántica pero cuyos orígenes datan en la mitología y la cultura clásica, podemos detectar que su presencia no siempre sigue una misma línea comunicativa (Dijkstra, 1994). La literatura romántica consagró a la mujer fatal más malvada y perversa antes conocida (Praz, 1999), la pintura prerrafaelista exaltó la estética de las mujeres fatales y sirvió como epicentro para la configuración de la representación icónica de la mujer fatal (Bornay, 1999) y el cine, por su parte, aportó, gracias a la combinación del audiovisual, a una mujer fatal mucho más seductora y atractiva, configurando una canon estético más cercano al mundo del glamour y de la persuasión erótica que al propio carácter perverso que la había venido configurando (Canals, 2009; Autor, 2013; Cruzado-Rodríguez, 2015).

Con el auge de la ficción televisiva, la imagen de la mujer fatal adquiere un nuevo significado si tenemos en cuenta las necesidades del medio y el carácter de los productos televisivos. Mientras que el cine o la pintura abogaron por una cuidada puesta en escena y un especial interés en la representación rigurosa de la esencia del mito, la televisión rompe con los cánones establecidos y reinventa el personaje de la mujer fatal adaptándolo a las necesidades propias del género. 
La telenovela como género es capaz de cambiar las reglas, adaptar, parodiar y continuar siendo una novela (Mazzioti, 1996). En este sentido, la telenovela, atendiendo a los cuatro pilares que la sustentan: la continuidad, el melodrama, la pasión como herramienta de exaltación y la conclusión o final Cueva (1999), se nutre de la esencia de las mujeres fatales propias del discurso cultural, pero las configura de forma exaltada, apuntando a un personaje villano, antagonista, que sea capaz de mantener la pasión a lo largo del discurso, resultando de esta configuración nuevas alteraciones imperfectas de la configuración tradicional cultural. Esto es, al fin y al cabo, una intercambiabilidad de las partes (Adorno \& Horkheimer 1998; Rodríguez-Ferrándiz, 2008) de un producto como es el estereotipo y, por consiguiente, una exposición clara del funcionamiento lógico de las industrias culturales en el proceso de estandarización del producto cultural.

\section{Metodología}

El presente trabajo se caracteriza por aportar una investigación que pretende conjugar la visión semiótica del estereotipo de la mujer fatal en la telenovela con la estandarización propia del estereotipo, con el fin de conocer en profundidad cómo son y cómo se construyen las mujeres fatales en los discursos narrativos de las telenovelas latinoamericanas.

El objetivo fundamental es observar la presencia del estereotipo de la mujer fatal en la ficción televisiva latinoamericana y conocer las características formales básicas que se repiten en la explotación del cliché. Además, se pretende establecer y definir las nuevas dimensiones adquiridas por el estereotipo, a saber, qué aspectos se repiten, cuales se alteran y que proceso de estandarización cultural se aplica a la hora de configurar el estereotipo dentro del producto serializado como son las telenovelas.

Se trata, por tanto, de una investigación de carácter descriptivo cuya resolución nos aportara un marco analítico sobre la presencia evolución y explotación del estereotipo de la mujer fatal en el producto televisivo de ficción por excelencia en Latinoamérica. La metodología aplicada, con enfoque cualitativo, se ha basado en la revisión bibliográfica y la investigación documental mediante visionado de todas aquellas telenovelas que conforman la muestra. Dicha muestra, que se ha configurado aplicando un muestreo no probabilístico de conveniencia basado en el juicio del investigador, recoge 61 telenovelas (Tabla 1) la mayoría de las cuales son de origen mexicano, aunque se han incluido ejemplos puntuales de otros países debido a la relevancia y el impacto estimado. 


\begin{tabular}{|c|c|c|c|c|c|c|c|c|c|c|c|c|}
\hline 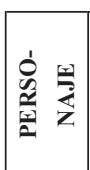 & 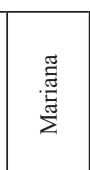 & 㝘 & 莺 & 隐 & 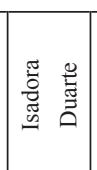 & 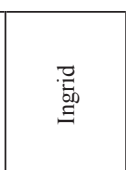 & 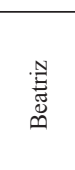 & 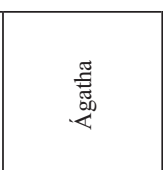 & 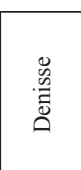 & 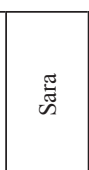 & 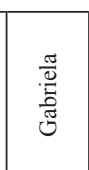 & 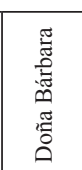 \\
\hline 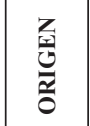 & 这 & 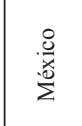 & 总 & 颜 & 这 & 这 & $\begin{array}{l}\overline{\bar{x}} \\
\overline{\tilde{n}}\end{array}$ & 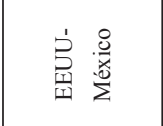 & 送 & 这 & 递 & 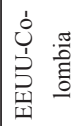 \\
\hline 安 & ڤ్రి & $\underset{\stackrel{d}{\Delta}}{\Delta}$ & ః્ત & ఫ్రి & 今్ & 商 & 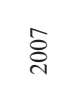 & ప్రి & 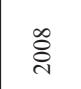 & 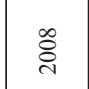 & 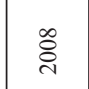 & 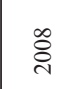 \\
\hline 总 & 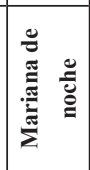 & 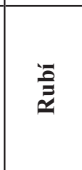 & 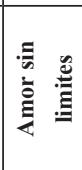 & 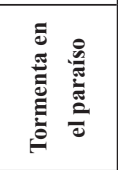 & 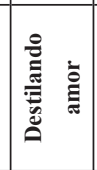 & 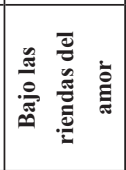 & 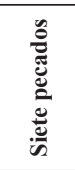 & 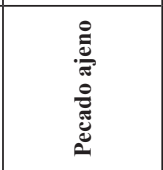 & 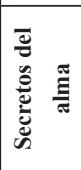 & 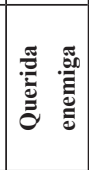 & 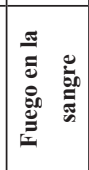 & 部 \\
\hline 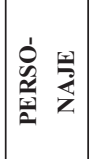 & 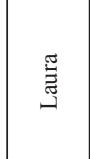 & 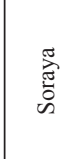 & 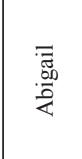 & 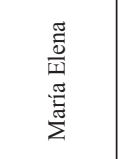 & 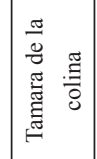 & 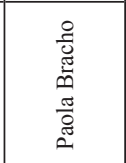 & $\frac{\frac{9}{5}}{\frac{5}{5}}$ & 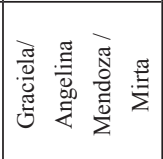 & 焉 & $\begin{array}{l}\text { 悉 } \\
\text { 形 }\end{array}$ & 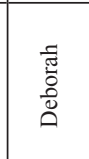 & 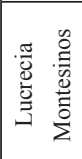 \\
\hline 啇 & $\frac{\stackrel{0}{\tilde{x}}}{20}$ & 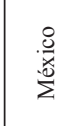 & 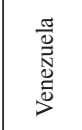 & 浐 & 这 & 这 & 这 & 丞 & 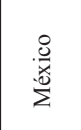 & 竞 & 竞 & 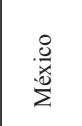 \\
\hline$\stackrel{8}{8}$ & $\stackrel{\text { }}{\circ}$ & $\stackrel{\text { }}{\circ}$ & $\stackrel{\circ}{\circ}$ & $\hat{\sigma}$ & $\stackrel{\infty}{\stackrel{\alpha}{\sigma}}$ & $\begin{array}{l}\infty \\
\stackrel{\alpha}{\sigma}\end{array}$ & $\stackrel{\infty}{\circ}$ & $\stackrel{\infty}{\stackrel{一}{\sigma}}$ & : & ఫ্ণ & 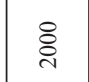 & $\overline{\mathrm{d}}$ \\
\hline 总 & & 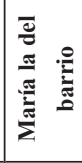 & 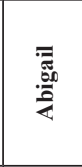 & $\stackrel{\vec{E}}{\vec{E}}$ & 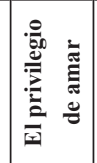 & 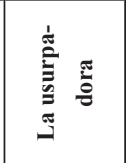 & 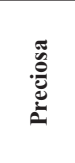 & $\begin{array}{l}\sum_{\bar{\pi}}^{\frac{\pi}{\pi}} \\
\triangleq \\
\Xi\end{array}$ & 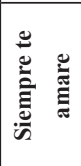 & 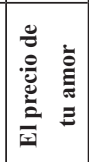 & 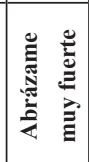 & 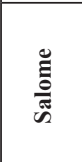 \\
\hline 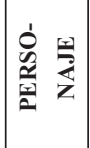 & 営 & 菢 & 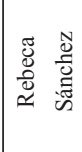 & 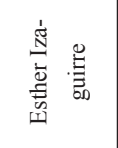 & 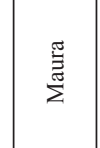 & 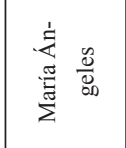 & 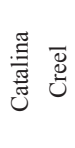 & 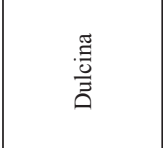 & 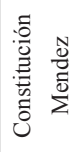 & 总 & 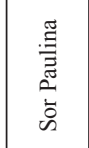 & 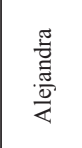 \\
\hline 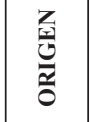 & $\frac{.8}{\tilde{x}}$ & : & 递 & 遃 & 浐 & 这 & 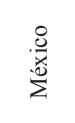 & $\stackrel{\frac{8}{x}}{\frac{.0}{2}}$ & 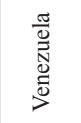 & 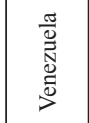 & 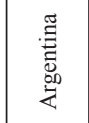 & $\frac{.8}{\frac{8}{x}}$ \\
\hline 安 & ถั & 合 & $\stackrel{\Re}{\sigma}$ & ڤે & $\stackrel{\leftrightarrow}{\stackrel{a}{\sigma}}$ & $\stackrel{\infty}{\stackrel{\alpha}{\sigma}}$ & $\begin{array}{l}\stackrel{\circ}{\Omega} \\
\stackrel{2}{a}\end{array}$ & $\stackrel{\infty}{g}$ & $\begin{array}{l}\infty \\
\stackrel{\infty}{\sigma}\end{array}$ & $\stackrel{\text { aे }}{\sigma}$ & $\stackrel{\text { }}{\stackrel{a}{\sigma}}$ & $\stackrel{\text { aे }}{a}$ \\
\hline 家 & 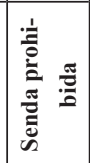 & 苞 & 㺃 & 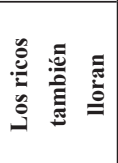 & 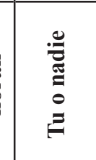 & 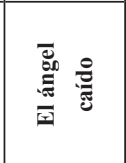 & 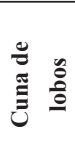 & 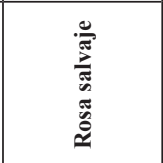 & 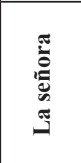 & 竧 & 焉 & 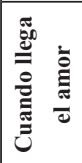 \\
\hline
\end{tabular}




\begin{tabular}{|c|c|c|c|c|c|c|c|c|c|}
\hline 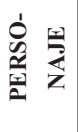 & $\stackrel{\widetilde{Z}}{\approx}$ & 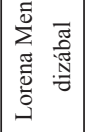 & $\stackrel{\mathscr{ٌ}}{\Xi}$ & 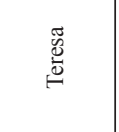 & 胥 & 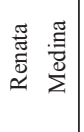 & 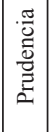 & & \\
\hline $\begin{array}{l}\text { Z } \\
\text { 䍖 } \\
\text { 종 }\end{array}$ & 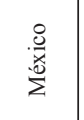 & 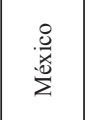 & 递 & 这 & 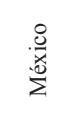 & 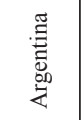 & 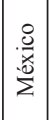 & & \\
\hline 号 & 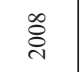 & $\stackrel{\text { ڤे }}{\text { ¿े }}$ & ळे & $\stackrel{\circ}{\stackrel{\sim}{\sim}}$ & $\stackrel{\circ}{\stackrel{\sim}{\sim}}$ & $\stackrel{\circ}{\circ}$ & $\stackrel{\circ}{\stackrel{\sim}{*}}$ & & \\
\hline 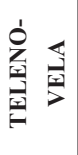 & 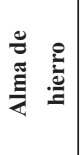 & 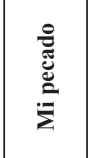 & 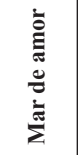 & 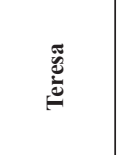 & 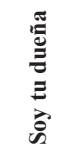 & 离 & 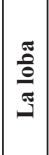 & & \\
\hline 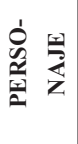 & $\cong$ & 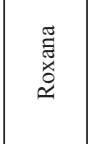 & 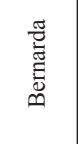 & 莹 & 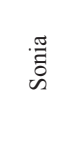 & 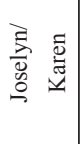 & 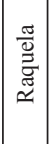 & 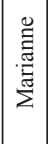 & 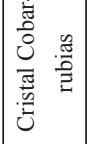 \\
\hline 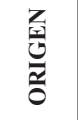 & $\begin{array}{l}\overline{\bar{n}} \\
\text { 馬 }\end{array}$ & 总 & 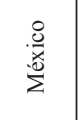 & 总 & 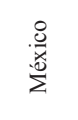 & 总 & 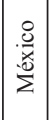 & 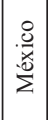 & 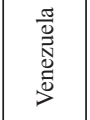 \\
\hline 多 & $\overrightarrow{\stackrel{\circ}{~}}$ & $\overrightarrow{\stackrel{े}{े}}$ & ઠิ & ڤ్ & ڤ్ & ڤ్ & 灾 & 灾 & ڤ్ \\
\hline 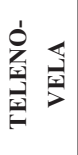 & 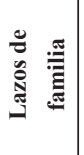 & 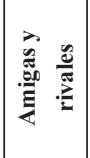 & 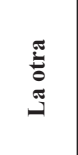 & 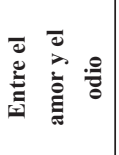 & 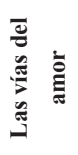 & 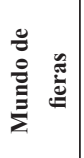 & 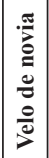 & 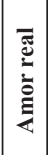 & 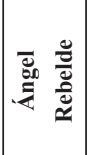 \\
\hline 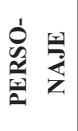 & 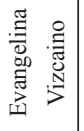 & 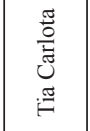 & 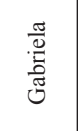 & 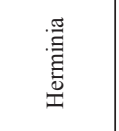 & 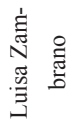 & 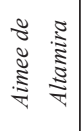 & 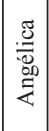 & 递 & 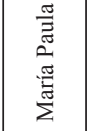 \\
\hline 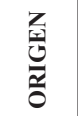 & 递 & 递 & 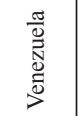 & 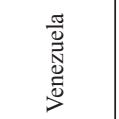 & 总 & 总 & 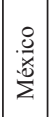 & 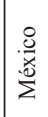 & 递 \\
\hline$\stackrel{\circ}{8}$ & $\vec{\sigma}$ & $\vec{\sigma}$ & ऽ̆ & ऽ & & $\tilde{\sigma}$ & 吉 & $\stackrel{2}{2}$ & 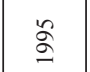 \\
\hline 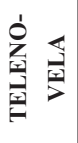 & 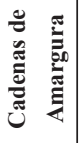 & 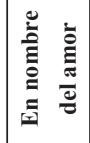 & 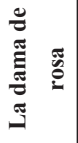 & 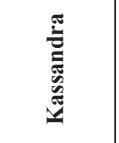 & 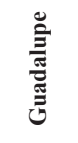 & 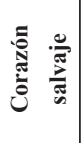 & 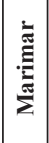 & 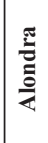 & 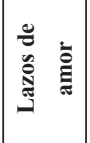 \\
\hline
\end{tabular}


Una vez realizado el visionado analítico de la muestra, se ha procedido a la clasificación de datos, atendiendo a dos procesos diferenciados: en primer lugar, se han extraído del visionado los casos de análisis que, según el juicio del investigador y previa documentación alrededor del significado del estereotipo de la mujer fatal, se pueden considerar personajes afines o cercando al estereotipo, atendiendo al papel que desempeñan y su personalidad en el seno de la narración. Detectados los casos de análisis, se han analizado individuamente los perfiles mediante un cuestionario creado ad hoc, en el que se diferencian las siguientes variables: a) construcción física del personaje, b) psicología del mismo, c) rol del personaje en la narración, y d) relación e interacción con otros personajes fatales de la trama. Estas variables han derivado en otras sub-variables que conforman la configuración de los personajes, entendiéndose estas sub-variables como elementos propios que sirven para disponer la estandarización del estereotipo en las telenovelas analizadas (Tabla 2).

Tabla 2: Variables y casos en la configuración del personaje.

\begin{tabular}{|l|l|}
\hline VARIABLE DE ANÁLISIS GENERAL & \multicolumn{1}{c|}{ CASOS DETECTADOS } \\
\hline Según la construcción física & $\begin{array}{l}\text { Las bellas fatales } \\
\text { Las fatales maduras } \\
\text { Las lolitas }\end{array}$ \\
\hline Según su psicología & $\begin{array}{l}\text { La asesina (sanguinaria) } \\
\text { La maquiavélica (calculadora) }\end{array}$ \\
\hline Según relaciones con otros personajes & $\begin{array}{l}\text { La fatal solitaria } \\
\text { La fatal aliada } \\
\text { Agrupación de fatales }\end{array}$ \\
\hline Según su papel en la narración & $\begin{array}{l}\text { La fatal antagonista } \\
\text { La fatal protagonista } \\
\text { La fatal efímera }\end{array}$ \\
\hline
\end{tabular}

Fuente: elaboración propia.

\section{Resultados}

Los resultados obtenidos tras la realización del análisis cualitativo en profundidad nos permiten confirmar, a priori, que existe una estandarización en la construcción del personaje y del discurso alrededor de la mujer fatal en la telenovela y que dicha estandarización viene dada por la introducción de alternaciones que muestran al personaje como distinto al estereotipo original pero que, al fin y al cabo, supone una alternación premeditada del mismo, en cumplimiento de un proceso de intercambiabilidad de las partes y pseudoindividualización (Adorno \& Horkheimer, 1998).

Este hecho se entiende como una expansión del proceso estandarizador a la ficción televisiva, en este caso, a la telenovela entendida como el producto televisivo de ficción por excelencia en Latinoamérica.

Los resultados del análisis de la construcción del personaje y su relación con el discurso adquieren cuatro vertientes, que se corresponden con las variables de análisis y que se desarrollan a continuación: 


\subsection{De la construcción física de la mujer fatal}

Si comentamos la construcción de la imagen física de la mujer fatal, hemos podido observar que se realiza, fundamentalmente, conjugando la belleza propia del personaje con las alteraciones relacionadas con su edad. Así, partiendo de la premisa de que las mujeres fatales de telenovela surgen como una herencia directa de las fatales cinematográficas (Autor, 2013), no es de extrañar que la belleza sea una característica intrínseca al personaje. Ellas, las fatales, saben que son hermosas y, por eso mismo, consiguen expresar en sus rostros la seducción que necesita el personaje que interpretan. Los ejemplos más relevantes se aprecian en el personaje de Rubí en la telenovela del mismo nombre (en todas sus versiones), en Marcia Hernández de Tierra de pasiones, en Denisse y Laura en Secretos del alma, en Irama en Soy tu due$\tilde{n} a$ o Joselyn en Mundo de fieras. Todas ellas gozan de una belleza que aprovechan para llevar a cabo sus ideas perversas y dotar a la trama de la acción necesaria para obtener el éxito. Además, dentro de esta variable, distinguimos dos tipos de bellezas fatales diferenciadas: por una parte, las mujeres fatales que poseen de una seducción natural fruto de sus características físicas (por ejemplo, Constitución Méndez en $L a$ señora) y, por otra parte, aquellas fatales que, aunque con menor belleza y poder de seducción, asumen roles de féminas muy recargadas, muy adornadas, excesivamente maquilladas y vestidas de forma exuberante. Se trata de mujeres fatales forzadas que se juegan todo en su imagen y velan por su "perfección" física (por ejemplo, Minerva en Destilando amor, Ingrid en Bajo las riendas del amor, Mónica en Amor sin límites o Sandra en El precio de tu amor.)

Dentro de la construcción física de la mujer fatal, destaca, en segundo lugar, la existencia de mujeres fatales maduras. Estas mujeres, que suelen oscilar entre los cuarenta y sesenta años (las bellas fatales oscilan alrededor de los treinta o menos) suelen vestir con ropas propias de su edad, poco exuberantes y evitando mostrar en exceso sus cuerpos. Han sustituido las cabelleras largas por recogidos y han cambiado las miradas sensuales por rostros serios, misteriosos, a veces fantasmagóricos que consiguen alzar su suspicacia y penetrar así en los personajes de su alrededor. Catalina Creel supone un icono de lo que sería la mujer fatal madura en las telenovelas analizadas. El rasgo más característico de este personaje que en la telenovela Cuna de lobos encarna la maldad más frívola y sin escrúpulos, era un parche que lucía siempre en uno de sus ojos para hacer eco de un problema ocular que impedía su correcta visión. Tras el éxito de Cuna de lobos (1986) fueron muchas las telenovelas que se 'estrenaron con una villana similar a Catalina Creel, como se observa en el personaje de Evangelina Vizcaíno en Cadenas de amargura (1991), Luisa Zambrano en Guadalupe (1993) o Isaura en Amarte es mi pecado (2004). El personaje de Carlota Espinoza en El nombre del amor, rompería el paradigma de las fatales maduras al mostrarse realmente guapa, con un cuerpo exuberante y una mirada perfilada y persuasiva que refleja, tal vez, la más bella de las fatales maduras conocidas.

En tercer lugar, la construcción física de la mujer fatal nos acerca a las jóvenes fatales, que son representadas como personajes infantiles, ingenuos, con rostros finos y delicados, con sonrisas inocentes y caras de muñecas. Ellas aprovechan su falsa inocencia para conseguir sus objetivos. No son niñas respecto a la edad, son personajes ingenuos desde el punto de vista de la representación y la puesta en escena. Los ejemplos más significativos son el personaje de Alejandra en Cuando llega amor, Valeria en Preciosa o Marianne en Amor real, todas ellas más cercanas a las lolitas 
de la literatura romántica que a las mujeres fatales tradicionalmente representadas en la telenovela.

\subsection{Sobre el perfil psicológico de la mujer fatal}

Partiendo de la premisa de que las mujeres fatales de las telenovelas son sanguinarias y asesinas sin escrúpulos que actúan de manera solitaria, rápida y directa, una de las telenovelas más antiguas analizadas, El ángel caído (1985), ya devuelve un caso en el que María de los Ángeles abandera esta tendencia sanguinaria matando primero a su marido en la noche de bodas para hacerse dueña de su herencia y luego a su tío con las mismas intenciones.

Cristal Covarrubias en Ángel rebelde actúa como una verdadera artista del asesinato. Cristal asesinó a su propia abuela, a Patricia, a Ernesto y Rómulo, los personajes masculinos que daban continuidad a la serie, $y$, a su paso, dejó alguna víctima más entre los personajes secundarios de la narración. También Isaura en Amarte es mi pecado, interpreta un rol sanguinario sin precedentes, recordando a una de aquellas vamps míticas literatura germana, encarnando a una sanguinaria bruja homicida. Otras como Marcia en la telenovela Marina de noche, Bernarda en La Otra o María Paula en Lazos de amor siguen el estilo frio y calculador sin precedentes y se postulan como asesinas crueles y sin escrúpulos capaces de todo por conseguir sus objetivos.

Aunque el asesinato se ha convertido en una de las características más arraigadas en el estereotipo de la mujer fatal en las telenovelas, no siempre las fatales terminan llevando al extremo su malicia. Existen casos en los que la fatalidad femenina tiene una medida y, la personalidad del personaje es más bien una personalidad maquiavélica, capaces de controlar su ira. Se trata de mujeres fatales que pretenden alcanzar sus objetivos gracias a su poder de persuasión, pero no llegan a ser víboras activas y sanguinarias. Paola Bracho en La usurpadora, nunca asesinó a nadie, pero fue una villana sin vergüenza ni pudor en sus actos, reflejando a la mujer fatal tradicional: utilizando su belleza y las palabras dulces para manipular a cualquier personaje y la amenaza como alternativa para mantener el control.

También Teresa, en la telenovela del mismo nombre responde a este tipo de mujer fatal, construida sobre el discurso retorcido, maquiavélico y malicioso, pero sin llegar a ser cruel. encaja en la categoría de fatales maquiavélicas. La malicia de Teresa recae en su capacidad de seducción y persuasión, pero es incapaz de matar o hacer daño físico a nadie. El desenlace la llevará a arrepentirse de todo el mal que ha hecho, pero será tarde. Otros ejemplos, como se aprecia en Corazón Salvaje mediante el personaje de Aimée, la malicia de la mujer fatal vendrá dada por el ansia de amor, lejos del carácter cruel de otras colegas de narración.

\subsection{De su relación con el resto de personajes}

Tradicionalmente, la mujer fatal ha actuado sola e independientemente. La personalidad perversa del personaje implica el secretismo de sus intenciones, por lo que no necesita ayuda para exaltar su fatalismo. El análisis devuelve multitud de casos en los que el personaje fatal actúa desde la soledad que caracteriza a su idiosincrasia. Evangelina Vizcaíno en Cadenas de Amargura o Tía Carlota en En nombre del amor asumen roles fatales solitarios después de destruir a su único apoyo en la trama mientras que Bárbara 
Greco en Mañana es para siempre es capaz de llevar de forma solitaria su crueldad extrema, fruto de su coraje perverso que caracteriza al personaje.

En otros casos analizados observamos como las mujeres fatales no son capaces de actuar solas y necesitan de la colaboración de otros personajes de la trama. Estos personajes suelen presentar un grado de fatalismo inferior pues, a pesar de su malicia, necesitan el apoyo de otros aliados para sentirse capaces de actuar y plasmar el rencor y la venganza en la trama. Esta búsqueda de colaboración para desempeñar las funciones de mujer fatal se lleva a cabo de distintas formas, por ejemplo, mediante el sometimiento de personajes benévolos, como hace Doña Juana en Alborada, sometiendo a la criada Modesta hasta el punto de que esta le ayuda a suicidarse cuando decide quitarse del medio o Leopoldina en Rosa Salvaje, una criada divertida que se dedica a extraer toda la información posible para hacérsela llegar a su dueña y para ello buscará alianzas fatales entre los personajes. Otras alianzas fatales se caracterizan por la unión de la mujer fatal con otro personaje antagonista, malvado y con objetivos similares, como se aprecia en la alianza entre Bárbara y Tony en $E l$ color del pecado, la telenovela Rosalinda en la que, la Valeria tiene como aliada a Bertha, la criada, o Denisse Junot y Olimpo, un hombre despiadado y antagonista en la telenovela Secretos del alma.

Pero si hay que destacar un hecho innovador que devuelve el análisis en relación al protagonismo de la mujer fatal es la existencia de agrupaciones de villanas que unen sus esfuerzos para, mediante la persuasión, la seducción y el sometimiento de personajes, conseguir objetivos comunes. Se trata de una tendencia latente, en especial en las telenovelas más recientes. La coalición fatal se configura mediante la puesta en escena de dos villanas en igualdad de condiciones, no sólo en cuanto al poder de seducción sino también en el marco de sus actuaciones. El análisis devuelve ejemplos como el tándem de Joselyn y Karen en Mundo de Fieras, Graciela, Angelina y Mirta en Luz María, la unión de Lorena y Renata en Mi pecado o Denisse Junot y Cecilia en Secretos del alma.

\subsection{De su protagonismo en la narración}

Tradicionalmente, el papel de la mujer fatal en telenovela ha sido el de antagonista puesto que es el personaje que se opondrá al triunfo de los protagonistas. Desde Gilda en Siempre te Amaré, Gabriela en Fuego en la sangre, Inés en Mar de amor o Mariana en Tormenta en el paraíso, todas ellas y muchas más responden al perfil tradicional antagonista, cuyo objetivo final será evitar el triunfo del bien y obstaculizar toda posible felicidad de los protagonistas.

No obstante, el análisis nos devuelve muchos casos en los que la mujer fatal en la telenovela adquiere el papel protagonista. Estas villanas son muy carismáticas, se sitúan la cabeza de las tramas para enfatizar sus maldades y conducir el hilo argumental de la pieza.

En los inicios de la telenovela ya podíamos distinguir a una mujer fatal protagonista, interpretada por Nora en Senda Prohibida, reflejando la imagen de una chica de barrio que será capaz de todo para conseguir una posición social privilegiada. Otro ejemplo posterior es el de Rubi (en todas las versiones). Rubí es una mujer hermosa que a lo largo de la telenovela busca salir de la miseria. Para ello, será capaz de traicionar al hombre al que ama, su mejor amiga, y desarrollar un sinfín de tramas guiadas por su carácter ambicioso y calculador. 
También el ejemplo de Teresa (en sendas versiones analizadas) la protagonista, se propone alcanzar una posición social superior y para conseguirlo no dudará en ningún momento en seducir a todos los hombres que se ponen a su alrededor, siendo la propia Teresa la protagonista principal de todas y cada una de las tramas. La telenovela Matrona, por su parte, muestra como mujer fatal consagrada a la protagonista, Renata Medina, quien guía la evolución de la trama con la idea de vengarse por la muerte de su madre.

En algunos casos, aunque con menor incidencia, las mujeres fatales sólo asumen un papel secundario y efímero no tienen mayor importancia en la narración. A pesar de que no abundan en exceso las fatales que quedan relegadas segundo lugar, merece la pena destacar algunos ejemplos como Casandra donde la madrastra Herminia, aunque se posiciona como villana desde los inicios, no adquiere mucha importancia en el desarrollo de la trama. También en Alondra, Loreto representa el papel de mujer fatal pero sus apariciones son puntuales y sus acciones fatales son más bien secundarias.

\section{Conclusiones}

Los resultados expuestos nos permiten afirmar, en primer lugar, que la construcción discursiva de la telenovela manifiesta la representación más seductora de la mujer fatal, dando lugar a la reinvención de la tradicional antagonista en una femme fatale evidente, perceptible y totalmente estandarizada.

El género de la telenovela llega al extremo la configuración de la mujer fatal como se había entendido a lo largo de la tradición cultural y desarrolla una imagen que recupera las raíces más puras del mito, aportando mujeres fatales excesivamente perversas y malignas. Esta configuración, influenciada evidentemente por la estética cinematográfica pero vinculada a la perversidad más mortífera de las mujeres fatales literarias, supone uno de los aspectos más relevantes en cuanto a la aportación de las telenovelas en la construcción cultural del mito de la mujer fatal.

Como se ha podido constatar en el análisis, los rasgos más significativos que aportan las telenovelas a la divulgación industrial-cultural del mito de la mujer fatal residen, por una parte, en la innovación de mujeres fatales maduras, que, a pesar de alejarse del patrón tradicional de belleza y seducción natural, responden a las lógicas más puras del carácter letal de la mujer fatal. Se trata, pues, de una alteración de la esencia clásica del mito que, a pesar de romper con el patrón estético de la mujer fatal, se convierte en una nueva configuración del discurso estandarizado alrededor de estos personajes.

En segundo lugar, destaca la innovación en la relación de la mujer fatal y el resto de personajes del discurso. La tradición cultural ha apostado por una configuración de la mujer fatal alrededor de la soledad, la independencia y el aislamiento, como respuesta a las necesidades intrínsecas a la perversidad del personaje. No obstante, la telenovela rompe con la construcción solitaria de la mujer fatal y aporta las alianzas más alternativas y los tándems más perversos conocidos en la tradición cultural. Ahora bien, no podemos obviar que esta innovación surge de la importancia del personaje antagonista dentro del género de la telenovela y la búsqueda de la innovación en la trama. En cualquier caso, resulta curioso que sea el propio producto televisivo seriado el que ponga de manifiesto la innovación, teniendo en cuenta que, por otro 
lado, el género lleva al extremo la malicia y la perversidad de la mujer fatal configurada en otras épocas y manifestaciones.

En cuanto a la psicología del personaje, la telenovela apuesta por la versión más sanguinaria y cruel de la mujer fatal. En la mayoría de casos analizados se ha constatado que la mujer fatal no solo es una mujer seductora que utiliza sus armas de persuasión para conseguir un objetivo, sino que se convierte en una asesina sin precedentes, llevando al extremo el carácter más perverso encarnado por el personaje a lo largo de la tradición cultural. Vemos, por tanto, que el resurgir de la mujer fatal en la telenovela respira vinculaciones directas con las fatales más perversas que surgieron de la misoginia romántica (casos realmente sanguinarios y crueles como fueron la Matilde de Lewis o Adelaida en la obra Götz von Berlichingen de Goethe). Este fenómeno, tiene su justificación en las necesidades morales de la época, y la necesidad de encarnar en la imagen del personaje antagonista (en este caso, el antagonismo fatal) la personificación del mal más perverso, más demoníaco y cruel.

Para terminar, en cuanto al protagonismo del personaje fatal en los discursos narrativos ha quedado patente que, a pesar de ser la mujer fatal de las telenovelas la perfecta antagonista y la villana sin precedentes, lo cierto es que adquieren cierta importancia las mujeres fatales protagonistas, rompiendo el esquema narrativo tradicional de protagonismo positivo y antagonismo negativo. La mujer fatal se convierte, pues, en un personaje que encarna el protagonismo antagónico de una forma totalmente consciente y que, con ello, configura un nuevo personaje totalmente independiente capaz de desarrollar la narratología del discurso desde la perversidad y la maldad.

En síntesis, el presente trabajo deja patente la existencia de una configuración personalizada de la mujer fatal en el discurso de las telenovelas, evidenciando la capacidad de la telenovela para conjugar dos extremos opuestos de mujer: la mujer fatal, la villana por excelencia en contraposición a la buena mujer, la fiel y correcta, en un intento moralizador de dejar patente del triunfo del bien sobre el mal.

\section{Referencias bibliográficas}

Adorno, T. \& Horkheimer, M. (1998). Dialéctica de la ilustración. Fragmentos filosóficos. Madrid: Trotta.

Allen, V. M. (1983). The Femme Fatale. Erotic Icon. New York: Whitston.

Bornay, E. (1990). Las hijas de Lilith. Madrid: Cátedra.

Canals, M. (2009). La dona fatal del cinema espanyol: 1939-1951. (Tesis Doctoral). Barcelona: Universitat Ramón Llul. Departament de Comunicació Social. Facultat de Comunicació Blanquerna. Recuperado de: https://goo.gl/RNoHHp

Carvajal, L. \& Molina, X. (1999). Trayectoria de la telenovela latinoamericana. El caso de la telenovela brasileña. Revista Latina de Comunicación Social, $\mathrm{n}^{\circ} 21$

Cruzado-Rodriguez, M.A. (2004). El Mal Tiene Nombre de Mujer: del Olimpo a la Meca del Cine." En Arriaga, M. y Estévez, M. (Eds.), Espejo de la Cultura: Mujeres e Iconos Femenimos (pp. 31-45). Sevilla: Arcibel.

Cueva, A. (1999). Lágrimas de cocodrilo: historia mínima de las telenovelas en México. México: Tres Lunas.

Dijkstra, B. (1994). Ídolos de perversidad. La imagen de la mujer en la cultura de fin de siglo. Barcelona: Debate. 
Gallego Ayala, J. (2013). De reinas a ciudadanas. Medios de comunicación, ¿motor o rémora para la igualdad? Barcelona: Aresta.

González-Ovies, A. (1994). Mito: masculino singular. En Caramés, J.L. y González, S. (Eds.), Género y sexo en el discurso artístico (pp. 379-390). Oviedo: Universidad de Oviedo.

Gonzalez-Rubín, B. (2007). La telenovela como fenómeno social. Recuperado de: https:// goo.gl/Cj8uso

Hidalgo-Marí, T. (2013). De Pandora i altres mals: La divulgació industrial-cultural del mite de la dona fatal. [Tesis Doctoral]. Alicante: Universidad de Alicante.

Hidalgo-Marí, T. (2015). El resurgir de la mujer fatal en publicidad: la reinvención de un mito. Cuestiones de género: de la igualdad y la diferencia, (10), 394-418.

Hilmes, C. (1990). Die Femme fatale. Ein Weiblichkeitstypus in der nachromantischen Literatur. Stuttgart: Metzler.

Houvenaghel, E.; Monballieu, A. (2008). El eterno retorno de la mujer fatal en 'Circe' de Julio Cortázar. Bulletinof Hispanic Studies, 85 (6), 853-866.

Lataban, A. (1995). Consumo de telenovelas por estudiantes de universidades privadas. Mexico Puebla: Universidad de las Américas Puebla.

Lippman, W. (2003). La opinión pública. Madrid: Langre.

Martin-barbero, J. (1992). Televisión y Melodrama. Bogotá: Tercer Mundo Editores.

Mazzioti, N. (1996). La industria de la telenovela. La producción de ficción en América Latina. Barcelona: Paidós.

Miller, A.G. (1999). Historical and Contemporary Perspectives on Stereotyping. En Miller, E. (Coord), In Eye of the Beholder. Contemporary Issues on Stereotyping. New York: Praeger.

Millet, K. (1991). Política sexual. Madrid: Cátedra.

Morin, E. (1966). El espíritu del tiempo: ensayo sobre la cultura de masas. Madrid: Taurus.

Otto, W. (1979). Los dioses de Grecia. La imagen de lo divino a la luz del espíritu griego. Buenos Aires: Eudeba.

Praz, M. (1999). La carne la muerte y el diablo en la literatura romántica. Barcelona: Quaderns Crema.

Rodríguez-Ferrándiz, R. (2008). Màscares d`allò nou: dialèctica de les indústries culturals. Papers d'art, 94, 5-46

Roura, A. (1993). Telenovelas de pasión. El sexo del culebrón. Barcelona: Gedisa.

Wolf, M. (1987). La investigación de la comunicación de masas. Barcelona: Paidós. 